\title{
Designing a Rate System for an Imaging Recharge Center
}

\section{Debby Sherman \\ Life Science Microscopy Facility, Purdue Univ., West Lafayette, IN dsherman@purdue.edu}

Presented at the M\&M 2007 Facility Operation \& Management Focused Interest Group session

As you all know, recharge: the price or rate a microscopy facility charges others to use their instruments, is a big topic on the MSA listserver and everybody struggles with designing rate systems. My talk is geared to U.S. labs and a lot of our restrictions regarding rates are not the same in Canada or other countries around the world. Our goal is designing recharge systems that will encourage facility use that will also recover the cost of the operation. How much you have to recover depends on your particular operation, your administration, and institutional requirements.

The basic approach to producing a rate charge system is really cut and dried-especially according to the accountants. You determine the supply and expense costs and anticipated use and you come up with a rate. Simple, straight forward and, if you do that, you probably will fail. So you go through exercises such as itemizing how much it costs for a particular procedure. You add in what you anticipate the labor could be, and you come up with a rate. Now, this may not be the same for every specimen placed in the instrument, but you hope it kind of averages out so that you don't have multiple rate scenarios for handling different types of specimens.

You put your computed rates into a spreadsheet, give it to the accountants. They start juggling it around and it ends up that your high edge TEM costs $\$ 10$ an hour and your low end TEM costs $\$ 50$ an hour. They've no concept of actually what the equipment is, what it costs to run it, why one is more desirable than the other, and why you need all these things in the first place.

Another approach is to determine your total yearly costs. You then come up with what you consider is an appropriate rate for your users for each instrument. You want to encourage use of the facilities rather than discourage them. The rate has to be-and this is what the bookkeepers have a hard time understanding - it has to be affordable. It has to be enticing. It cannot appeal to only those people who have a grant. It has to be appropriate for the new faculty members and others with minimal funding as well.

In preparation for this talk I sent 15 questions to two individuals whose job it is to help design recharge systems for centers throughout the university. They are supposed to know the answers. They passed them through our costing center people to try to get answers that would be acceptable to the university business office. Now these are the type of answers with no flexibility. The university wants to have policies that the granting agencies will find satisfactory if they are audited. The questions I gave and answers I received are as follows.

\section{Identical Rates:}

One major problem is satisfying requirements of granting agencies. Granting agencies want the rates to be identical for all users. This is across the board--NSF, NIH, DOE--whatever. They want to make sure that their funded users are paying the same as everybody else. They want also the full documentation and justification for the rates charged.

Question 1:. Can you have different rates at different times (Day vs night vs weekends)? - Possibly, providing costs are different at different times such as whether or not personnel are available for assistance. You have to be able to justify having different rates.
Question 2: Can you have daily or monthly rates ivi a sa number of hours or unlimited use?

This came up on the listserver recently, where a department or a laboratory paid a certain amount and they essentially got unlimited use for the specified time period. This can be used as a marketing tool; but you cannot recover funds based on this scheme and satisfy the federal granting agencies. You can say you have a monthly rate as an upfront payment for time but it must be based on a specific number of hours of use. If they go over it, they have to pay more money. If they go under it, then you have to give them a refund. You have to bill for exact time used.

Question 3: Can a department/center buy into a facility and get preferential rates? The initial buy-in can be used as a subsidy to offset the standard rates. But you must base that buy-in amount on the anticipated use. The center users then pay a discounted rate. The subsidy plus what the users in that department pay must equal the standard rate.

Question 4: Can some pieces of equipment be charged "hourly" while others are billed monthly or annually for unlimited use? Perhaps you want to charge for the larger items that have costly service contracts but do not want to worry about keeping track of smaller items. "Unlimited use" is the key. You may be able to do this for external customers but not for internal or sponsored programs in-house. Federal agencies require the tracking so users must be charged for actual use. So, there goes that scheme to make our life a little easier.

\section{Determination of rates.}

You derive an hourly rate based on the cost of the instrument. You total the expenses to maintain an instrument versus anticipated use and come up with a rate.

Question 5: Can you combine uses and costs associated with similar instruments that may not have equivalent use to derive an hourly rate? This is probably okay as long as you combine total use for both with total costs. It would result in a higher rate for the more heavily used instrument. For instance, you have two very similar TEMs but want to put most of the load on one and conserve the other. In this way when one is replaced the other will still be in good condition as a back-up.

Question 6: Can reasonable rates be set to encourage use of less desirable instruments to balance use? This is a situation where you have an older SEM and a new field emission SEM with all the bells and whistles. You want those who do not need the FESEM to use the older SEM and keep access to the FESEM for those that really need it. Also the older SEM is not on service contract but is maintained internally, so has minimal costs associated with it.

So how are we going to convince the accountants that we need to not only charge for the use of this low-end instrument, but justify that the field emission scope is getting a lot more use but charges need to be based on more than just use hours. If we were to charge based on use hours and service contract costs, I would end up charging \$10/ $\mathrm{hr}$ for this peak instrument and then give the other one away for free. My accounting people said "Yes, it is possible to pool funds to balance the use of similar instrumentation."

I need to convince my accountants-luckily they don't know one instrument from another-that they are similar instruments. I can justify lower rates on the older instrument based on age that will encourage people to use it when they don't need the high-end instrument and distribute over-all use.

Question 7: Is it possible to have reduced rates for private projects or new faculty who have not yet secured external funding? This comes up all the time with new projects. You are trying to encourage 


\section{FEI COMPANY}

TOOLS FOR NANOTECH

\section{See surface detail at the} nanoscale like never before Magellan $^{\text {TM }}$ XHR SEM

\section{Discover a world never seen before}

- Subnanometer resolution from $30 \mathrm{kV}$ down to $1 \mathrm{kV}$

- Surface details at low voltages you cannot see any other way

- Fast, accurate, precise analysis at higher voltages with high, stable current

- No compromises in sample size, shape, composition and preparation

- Simple and easy to use
This series of images from FEI's Magellan XHR SEM shows nanotubes imaged at $200 \mathrm{~V}$, from $10 \mathrm{k}$ to $600 \mathrm{k}$ times magnification. Note the contrast and surface detail that would not be possible on other SEMs. Images courtesy of Prof. Raynald Gauvin and Camille Probst, McGill University.

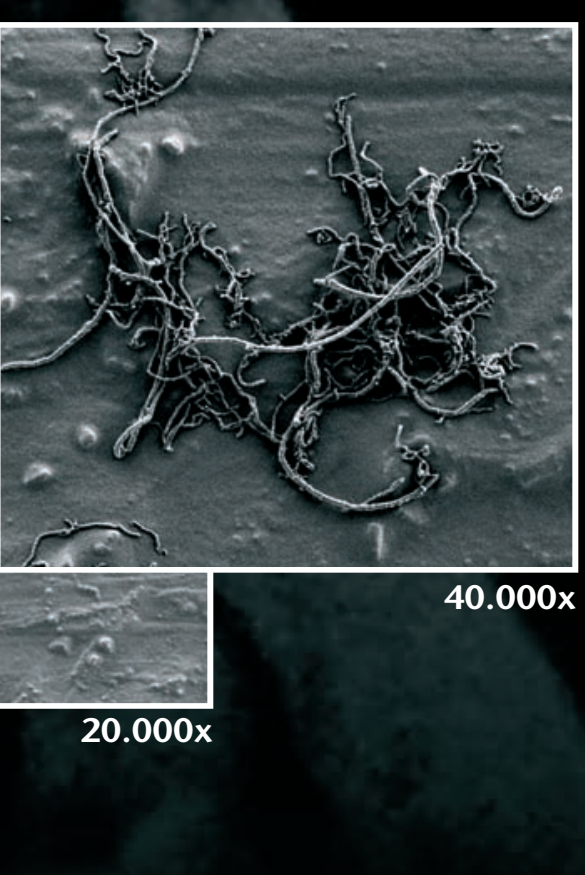

\section{Explore further at fei.com/magellan}


new faculty to come in and use the facility but they hesitate, not knowing if the techniques will work for them. You cannot build reduced fees into your rate. You can't give away free time (or even partially-free) services. Your users have to get seed funding from somewhere-that is what start-up funds are for. It has to be identical rates for everybody that uses the instruments. So, how do you handle it? We often bend a bit to help encourage use by not charging full labor rates for new technique development. This will help multiple users down the road so it can be written off to some extent.

\section{How are Salaries handled?}

Question 8: How can you account for technician's time for non-billable activities?

How do you account for all the routine chores such as general lab maintenance, making stock solutions, keeping records, going to the library to hunt-up new techniques. Staff must be able to take a coffee or bathroom break! In most cases, technical assistant's rates are already burdened with costs that cannot be charged to a specific project. Vacation time, sick time, all these other things that add to fringe benefits are all tied in to rate systems if you are trying to recuperate a technician's salary.

You can tie in labor with certain specific activities like fixation or embedding or sectioning. An additional assistance rate or "facility charge" can be charged for consulting during imaging or training equipment users. But this still leaves you with a lot of time that is really not billable to a specific person or a specific project. And that raises the rate for every project that has to be done. I think you all agree that it is really difficult to recover technicians' salaries through recharge.

Question 9: So what if salaries are covered by internal sources and not considered part of the re-charge recovery? Can you still charge a technical fee for assistance? Luckily, I'm in a situation where we have a couple of major salaries that are paid for by some of the colleges within the university. So we have these paid but we have some people come in as multi-users that do all their own work. We have a lot of people come in for service and they do none of their own work. You cannot recover salaries from internal sources and also charge for it through re-charge. So even though our salaries are paid, we are legally not allowed to charge for our time if we go in and do everything for somebody else.

How can this be handled? Well, it may be possible to charge a consulting or facility fee for additional services rather than a labor fee. This has to be based on the fact that more overhead is being attributed to these projects so it should be passed on to that specific investigator. So there are some ways to do it, but it is in the gray side of totally legal.

What about the use of facilities by or for external customers? This would include external not-for-profit as well as for-profit entities.

Now, my particular college was trying to do this rate scheme with the understanding that everybody had to be charged the same fee. The only difference between internal and external was indirect costs. All right? And I'm saying that is ridiculous. If I'm charging the person $\$ 30$ internal, that would be $\$ 45$ for an external client, which is well below commercial rate. We shouldn't be doing that. "Well," the answer was, "I guess you'll have to set your rates to the commercial rate and then the internal people will just have to find some way to subsidize their research." Obviously this was incorrect and has since been corrected.

Question 10: Can you use equipment purchased using federal funds for external work?

You certainly can provide external access under certain conditions according to Grants General Conditions \#215.34 that is applicable for all federal funding. During the time the equipment is used for the project or program for which it was acquired, the recipient can make it available to other people as long as it doesn't interfere with the original projects for which the grant was funded.

However, the grant recipient shall not use equipment acquired by federal funds to provide services to non-federal outside organizations for a fee that is less than private companies charge for equivalent services unless specifically authorized by Federal statute, for as long as the Federal Government retains an interest in the equipment.

Question 11: What limitations are there on the rates for external users? All external rates justifications should be based on comparisons with other universities offering similar services in a reasonably close geographic location. If there is not a market rate to go on, than it depends on your institution's policy. We have no commercial providers in our area so we have to set something that is reasonable. We also have to take into consideration that we do not want to undercut other universities with similar equipment. Our institution suggests three times the internal rate plus indirect costs, which is $52 \%$. This rate becomes much closer to what is reasonable in a commercial setting.

Question 12: Can there be a two-tiered rate for non-profit and for-profit institutions?

This can be done according to the costing people within my institution but it may differ with your organization. An example would be: Not-for-profit: internal rate + IDC or For-profit: market or multiplied rate $+I D C$

If the rates are identical, external sources are going to go to the place where they feel the most comfortable; where they are getting what they feel is the best service. So if you can provide the service, you will have the audience.

\section{Question 13: Can recharge centers make a profit?}

$\mathrm{No}$, recharge centers are not supposed to make a profit or accumulate surplus funds. According to federal granting agencies, rates are to be based on actual costs associated with use. At the end of the fiscal year, we are supposed to be even within a few percent. Plus, it is not possible to purchase new or replace old capital equipment. Capital equipment for us is anything over $\$ 2,500$. So how are we going to deal with this? Right now for biology there is not a grant program out there other than NIH or NSF major research instrumentation. Neither is appropriate for requesting a $\$ 50,000$ microtome.

Question 14: So assuming that, due to external use, the recharge center brings in more funds than is allowed, can these extra funds be used to purchase new or replace capital equipment? Yes, it can. You can use external funds as long as the external people are not using federal or state funds.

Question 15: Is it possible to have a surplus account where additional revenues can accumulate over a number of years to purchase equipment that is more expensive? The initial response was that you can do this but only if the surplus funds are from external customers. However, faculty members from our Management School reviewed this, and concluded that it is only reasonable business practice to front load a new instrument that is in high demand, and bank some of the revenue to pay for upkeep of that instrument when it is older and demand decreases. Our institution is reviewing some of these policies and time will tell if we can do this.

\section{Other Considerations for External Use}

Duty-free equipment entry: This is the where our Department of Commerce and U. S. Customs comes in. If you want to get dutyfree instruments in, you need to fill out an application stating that this 
Arizona State University 2009 Winter School

\section{High Resolution Electron Microscopy}

Monday January $12^{\text {th }}$ Friday January $16^{\text {th }}$

Interactive lectures and laboratories on the theory and practice of HREM and STEM, small probe formation, electron diffraction, image calculations and processing, electron energy loss and x-ray nanospectroscopy and focused ion beam. Demonstrations of environmental electron microscopy, focused ion beam methods and techniques of specimen preparation will be scheduled for the morning of January 16, 2009.

Instruments to be used include FEI Tecnai, CM 200, Nova-200, Topcon 002B, JEOL 2010F, 4000EX, 2000FX; and LEO 912.

The registration form (available at http://le-csss. asu.edu/workshops/) and check for the course fee (in the amount of $\$ 950.00$ ) payable to Arizona State University should be sent by November 1, 2008 to:

Beth Crespo

CHREM/LE-Center for Solid State Science

Arizona State University

Box 879506

Tempe, AZ 85287-9506

A limited number of graduate student scholarships are provided by EM manufacturers. To apply, see the web URL above.

\section{PELCO $^{\circledR}$ Silicon Nitride Membranes}

Next Generation $\mathrm{Si}_{3} \mathrm{~N}_{4}$ TEM Support Films with many advantages:

- Durable and chemically inert planar $50 \mathrm{~nm}$ substrate

- $3.0 \mathrm{~mm}$ circular frame compatible with standard TEM holders

- EasyGrip"' micro rough edges for ease of handling

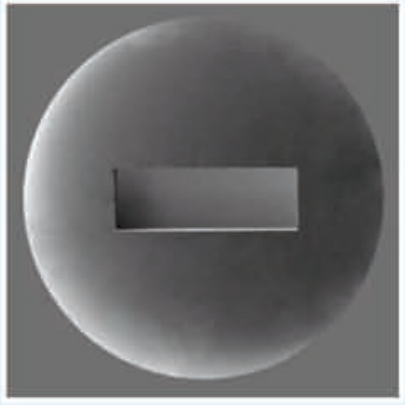

- Free from debris - no broken edges

- Large area support film: up to $0.5 \times 1.5 \mathrm{~mm}$

- Complimented with Aperture Frames and Blank Disks for nanotech experiments

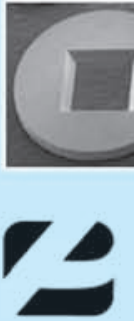
Aperture Frame

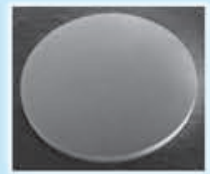

Blank Disks

\section{TED PELLA, INC.}

Microscopy Products for Science and Industry

$800-237-3526$

www.tedpella.com

\section{Let There Be}

$\mathrm{C} \mathrm{K} \alpha$

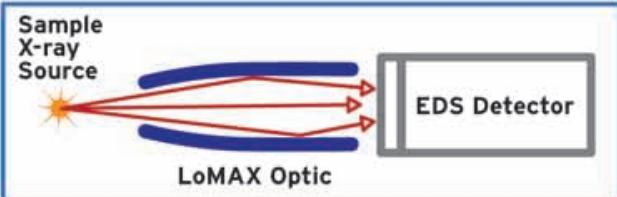

With LoMAX

Without LoMAX

\section{Discover LoMAX}

Attachable low energy $x$-ray EDS optic

- Fast easy installation - detector safety guaranteed

- Adapts to most detector sizes

- Boosts sensitivity up to $15 \mathrm{X}$ for energies $<1000 \mathrm{eV}$

- Quantitative analysis of Be, B, C, N, O, F

- Analyze heavier elements using $\mathrm{x}$-ray lines below 1000 ev

The new patented LoMAX low-energy $\mathrm{x}$-ray optic enables your EDS to see and analyze both light and heavy elements with $\mathrm{x}$-ray lines below $1000 \mathrm{eV}$. LoMAX is both easy and safe to install and remove it simply slides onto your EDS detector. It won't interfere with high-energy $\mathrm{x}$-rays. With LoMAX you will 'See the Light' - $x$-rays that is.
LoMAX. See the Light.

Call 866.581-XRAY for more information. WwW.parallaxray.com

US Patent \#6,442,231 B

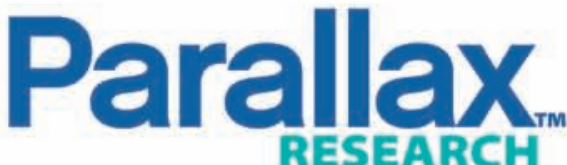


equipment is going to be used for academic, non-profit use only. It has to be approved by Commerce and by Customs in advance. Once approved, Customs needs to send verification to submitters so you know everything is okay. Commerce will need a copy of the Custom Entry Summary Form 7501.This is sent to Commerce by the submitter's import broker when the instrument has arrived. Then Commerce tells Customs that it is okay and Customs will finally admit it duty-free.

The paper work has to originate from the institution that is purchasing the instrumentation. The companies will certainly help you by telling you what is required, but they cannot originate it. It is being brought in and paid for by your funds and so you need to get it through Customs.

Restrictions on duty-free entry: Scientific equipment brought in duty-free is not to be used for-profit work for a period of five years after import. Some universities that know that their equipment is going have a large external user base will bring instruments in and pay the duty on them. If you want to be able to do external work legally on a new instrument for for-profit companies, you must pay the duty on it.

The duty can vary based on instrument and country of origin. And whether there are trade agreements with specific companies. For instance, duty is $3.5 \%$ of the sale price for anything from the European Union based on the final selling price.

Most of the above responses are based on institution interpretation of federal guidelines. Institutional and interpretation are the key words here. They vary from one institution to another. If a functionary at your institution says something that you don't understand, than ask for it in writing. Often the interpretation of the rules of the institution is a personal interpretation and not based on what is really there but what they think is there. So, do not be afraid to question your people.

Question: Can there be special rates for specific investigators?

This is a major problem. Occasionally an investigator will provide some research justification for a grant and then ask for preferential rates since they helped get the equipment. My response is that this is an institutional responsibility for individual faculty to help provide facilities for both their needs and their colleagues. So, no, they will not get preferential rates. If the equipment is in this facility and we are maintaining it and training people, then everyone pays the same amount. Otherwise, we will be in violation of the federal funding agency guidelines.

Question: What about external users who collaborate with an internal investigator or gives grants to someone within the institution. Do they pay internal or external rates?

They would pay the same rates that any internal person would as long as they have an internal funding code or an internal grant. We do charge academic institutions-external academic institutionsmore than internal investigators because they are not the ones that went out and got the equipment. They pay less than commercial users because I make sure they do; not because my rating people think they should. I feel that if you are collaborating with somebody that is in the university and you can arrange to transfer funds to that individual, the university will take out the overhead from that money just like for any other grant.

Question: Do investigators from institution $\mathrm{B}$ have to pay overhead to institution $A$ when using facilities at $A$ if they use federal grant funds from which their institution B has already removed overhead?

According to our institution, anybody that is outside has to pay to support our institution. Indirect rates are to pay for the electricity, the heat, the maintenance of our building, etc. The equipment is in our institution and if they are using our building, they have to pay it. They are going to have to work that out with the granting agency on their end.

Question: Is there any way to get around this double billing?

Our institution will waive indirect rates for any company, profit or nonprofit, if the total amount charged during the fiscal year is under $\$ 10,000$. As soon as it gets over $\$ 10,000$, they pay indirect on the entire amount from dollar one. In this way we can accommodate an occasional project, if they want to go through the paperwork of getting this done. It has to go through our Grants and Contract Office and be officially accepted in order to be able to do it.

Question: What about internal people who are actually doing research for a private company?

We have a lot of people within the university who have private for-profit companies. If I am aware that somebody is doing research directly for that for-profit company, they pay external rates. Sometimes you don't know because they have staff that works half for the university and half for the company. But most of them are very cooperative and understand that they should pay external rates for proprietary company research.

Question: Can an internal unit such as a research department or center arrange for subsidized rates for their staff?

You can charge reduced rates to the investigator and then charge the remainder of the standard rates to the internal unit. They're still paying standard rates. It is a matter of from where the money comes. A unit within the university is subsidizing them. This type of arrangement is common as part of a start-up package for new faculty.

Question: What happens if you make more than your expenses in a single year?

Well, our university does allow us to carry over a certain percentage. And, quite frankly, they don't necessarily determine every single fiscal year, exactly what it is as long as it's not a ridiculous amount. When I've had a major surplus, I've gone ahead and prepaid service contracts or ear-marked the funds for this purpose. I also buy extra supplies and non-capital equipment such as upgrading computers.

Question: How do you determine charges for specific equipment or services?

You have to use multiple years. You can't use one. I'm trying to get them to use a five-year period to determine a consistent use pattern.

Question: How can you handle maintenance costs when use declines as an instrument ages?

Check out the article that appeared in the July 2007 issue of Microscopy Today entitled: Developing a Financial Plan for the Long-term "Care and Feeding" of Major Equipment by Professor Charlene Sullivan and Alberto Rodriguez. This is an analysis of rate systems done by a member of our Krannert School of Management. The data was gathered from many microscopy labs throughout the USA and abroad.

There is a chart that shows the usage of a new microscope and what happens to use and rates as the microscope ages based on the cost of maintaining that instrument. You get to a point where it crosses the line. At some point, as the instrument ages, it starts costing you more to maintain the instrument than you can expect to get in revenue. The author's take on this is that we need to front-load the cost of an instrument and squirrel away some of those funds, so that we can pay for the service contract on that instrument when the luster has worn off. This is something that has to be an institutional policy.

\section{Acknowledgement}

We would like to acknowledge the contributions of Elizabeth Rulli and Whitney Beutel to this article. 


\title{
The new 2008-2010 EMS CATALOG is now available!
}

\author{
Exacting Research \\ demands only the \\ Highest Quality Products.
}

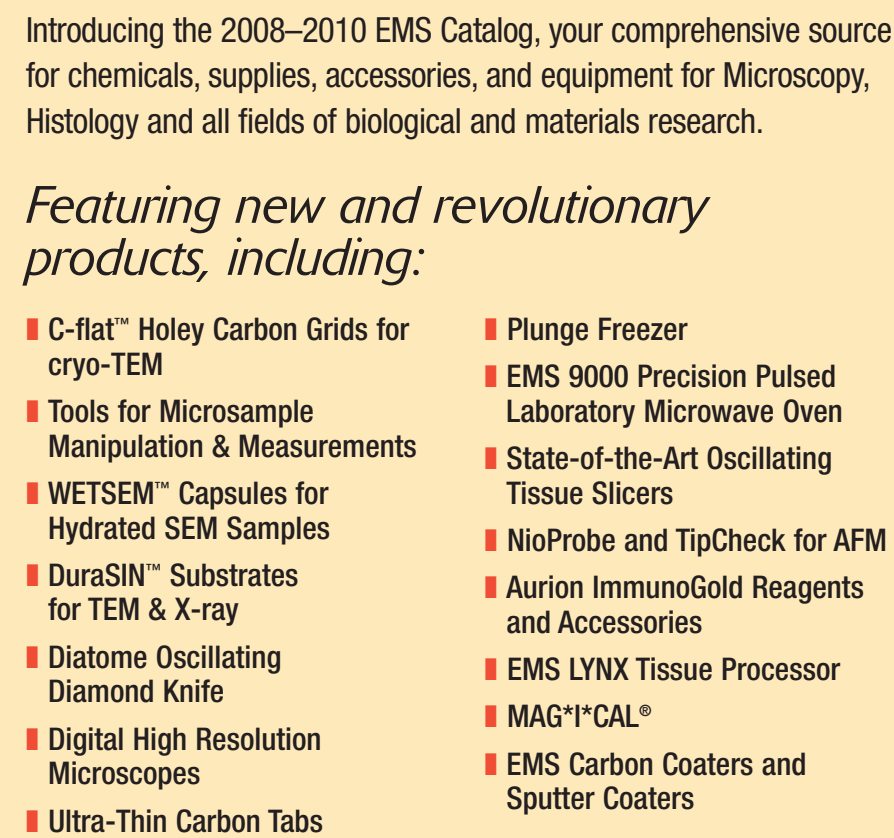
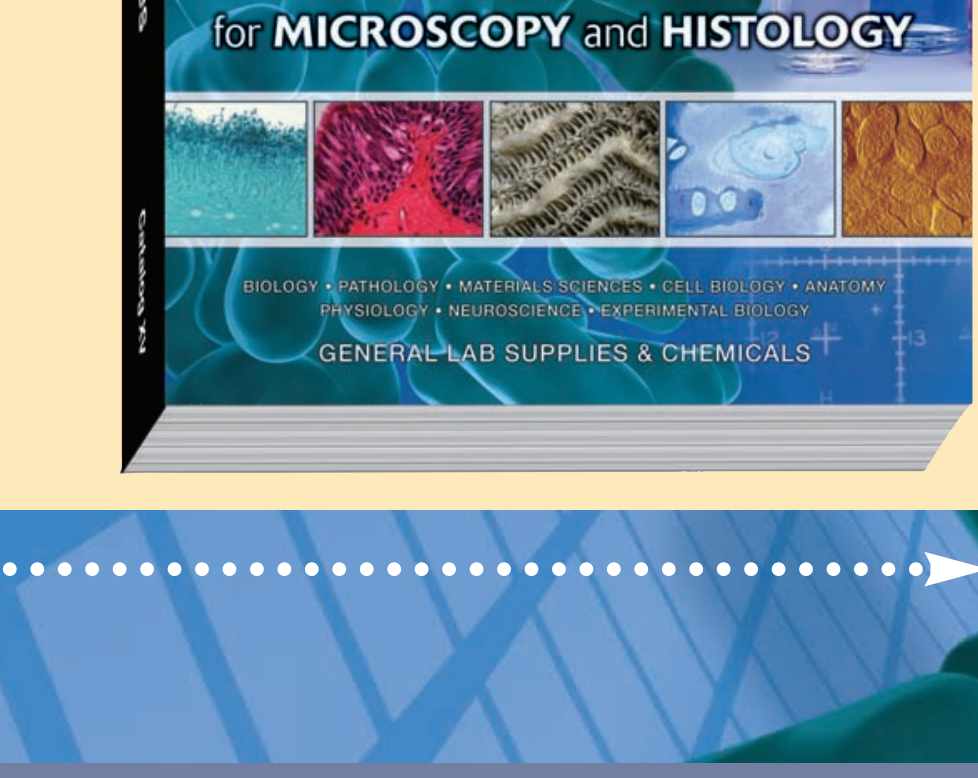

Your one-stop shop for the latest products and solutions for Microscopy and Histologyt

\section{Applieation Notes More Technical Support Enhanced Product Lines Revolutionary Products}
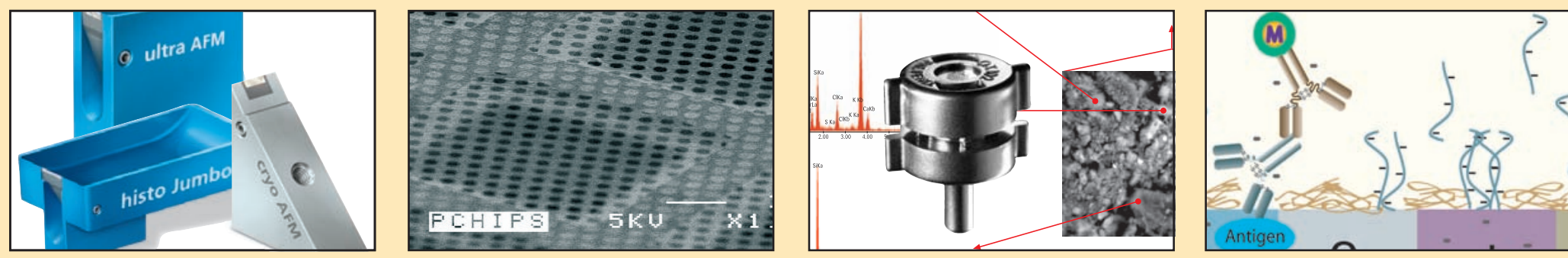

\section{QuantomiK WETSEM ${ }^{\text {TM }}$}

\section{To request our new catalog, please call or write us today, or visit us online at www.emsdiasum.com}

\section{Electron}

Microscopy

Sciences
P.O. Box $550 \bullet 1560$ Industry Rd. • Hatfield, Pa 19440

(215) 412-8400 • Toll Free: 1-(800) 523-5874

Fax: (215) $412-8450$ or 8452 email: sgkcck@aol.com • stacie@ems-secure.com www.emsdiasum.com 